\title{
Mesenchymal stem cell-derived exosome: a promising alternative in the therapy of Alzheimer's disease
}

\author{
Mengtian Guo ${ }^{1,2+}$, Zhenyu Yin ${ }^{1,2 \dagger}$, Fanglian Chen $^{3}$ and Ping Lei ${ }^{1,2^{*}}$
}

\begin{abstract}
Alzheimer's disease (AD) has been a devastating public health with the development of global aging. Approaches for reducing the current $A D$ epidemic are becoming a primary focus of human healthcare due to the lack of achieved lasting and complete remission strategies to treat AD with the characteristics of heterogeneity and complexity. Exosomes, which is the new emerging approach to intercellular communication, provide novel perspective on identified therapeutic strategies of AD. Mesenchymal stem cell-derived exosomes (MSC-exos) are emerging to be an appealing therapeutic tool for AD, with the donor-derived properties and the characteristics of minimal immunogenicity, effortless storage, nature delivery vehicles, and low risks of tumor formation based on the previous researches. In this review, we elaborate the mechanism of MSC-exos in the treatment of AD and discuss limitations in the clinical application.
\end{abstract}

Keywords: Mesenchymal stem cell, Alzheimer's disease, Exosome immunomodulation, Therapeutics

\section{Introduction}

Alzheimer's disease (AD) is the most common cause of dementia in the elderly, which contributes to $60-80 \%$ of total dementia population [1]. What is worse, the incidence of $\mathrm{AD}$ is rising continually [2]. As a neurodegenerative disease, $\mathrm{AD}$ is associated with high disability rate, resulting in more severe cognitive impairment than aging, which brings heavy burden to public administration and caregivers $[1,3]$.

$\mathrm{AD}$ is characterized by increased deposition of $\beta$ amyloid peptides and aggregation of hyperphosphorylated tau in neurofibrillary tangles (NFT) [4]. However, clinical symptoms vary with the region of brain injury. Typical clinical symptoms include progressive decline of episodic memory and executive functions [5]. In contrast, atypical

\footnotetext{
* Correspondence: leiping1974@163.com

${ }^{+}$Mengtian Guo and Zhenyu Yin contributed equally to this work.

'Department of Geriatrics, Tianjin Medical University General Hospital, Tianjin, China

${ }^{2}$ Tianjin Geriatrics Institute, Tianjin Medical University General Hospital, Tianjin, China

Full list of author information is available at the end of the article
}

clinical symptoms general occur in non-memory domains, presenting agnosia, aphasia and disturbed executive function [6]. From the therapeutic level, the existing medicine approved by Food and Drug Administration (FDA) for $\mathrm{AD}$ patients include three cholinesterase inhibitors (e.g., ChEIs; donepezil, rivastigmine, and galantamine) and an uncompetitive NMDA receptor 2 modulator (memantine). Unfortunately, the aforementioned medicine merely aims to improve quality of life and extend lifespan, but fail to halt disease progression [7]. Seeking novel therapeutic strategies for $\mathrm{AD}$ is urgent.

In recent years, mesenchymal stem cells (MSCs) have attracted much attention as the potential cell-based therapeutic tools due to its ability of migrating and mediating damage repair. MSCs facilitate neurological recovery and neo-angiogenesis through the secretion of neurotrophins and angiogenesis regulatory factors [8-10]. The ability of immunomodulatory effect, migratory capability, and regenerative potential of MSCs are confirmed in multiple disease models, such as atopic dermatitis, myocardial 
infarction, traumatic brain injury, and diabetes nephropathy [11-14]. However, accumulating researches suggest that the biodistribution of MSCs in the target organs is rare, and its therapeutic effect appears to be a consequence of the paracrine action [15-17]. The particles in the secreted proteins of MSCs are identified as exosomes through electron microscopy and proteomic analysis [18].

Exosomes (also called small extracellular vesicles (EVs)) are considered as a subtype of extracellular microvesicles with a diameter of 30-100 nm, including lipid bilayer membrane structure, and released by variety of cell types [19, 20]. Investigators primarily proposed the presence of extracellular vesicles in mammalian tissues or body fluids as early as in 1960s $[21,22]$, and the exosomes were considered as the unnecessary proteins for a long time [23, 24]. In fact, exosomes are able to reflect the state of the parent cell [25] and mediate intercellular communication through transporting biologically active cargo (including proteins, lipids, and nucleic acids) to recipient cells both in physiological and pathological conditions [26, 27]. Given the powerful biological functions, exosomes have been studied for applications as vaccines, immunosuppressant, or stimulators of repair and differentiation process [28].

Herein we outline the role of exosomes in AD treatment. Additionally, we elaborate the therapeutic properties of MSC-exos in $\mathrm{AD}$ and discuss the advantages and challenges of MSC-exos as a novel cell-free therapeutic agent.

\section{Exosome biogenesis, secretion, and uptake}

Enormous efforts were invested to clarify the mechanism of exosome biogenesis, secretion, and uptake (Fig. 1). Originally, extracellular constituents and cell surface proteins form the early sorting endosome (ESEs) through endocytosis along with plasma membrane budding inward. During the maturation process of ESEs, intraluminal vesicles (ILVs) begin to compose through invagination of the limiting endosomal membrane [29]. The formation of ILVs is controlled by several molecular machineries, mainly regulated by the machinery complex termed endosomal sorting complex required for transport (ESCRT) [30]. The ESCRT mechanism is composed of approximately 30 proteins which assemble into four complexes (ESCRT-0, ESCRT-I, ESCRT-II, ESCRT-III) and associated proteins (e.g.,Vps4, Alix, Tsg101) involved in the formation of ILVs [31, 32]. ESCRT-0 sequesters ubiquitinated cargo proteins, ESCRTI/II/III induce membrane deformation, and Vps4 complex ensure vesicle scission and recycling of the ESCRT-III complex [33]. Another pathway of exosomes biogenesis is generated independently of ESCRT machinery mechanisms, involving tetraspanins, ceramides, heat-shock proteins (HSPs), cholesterol, and phosphatidic acids [19]. Lipidmediated RNA loading into exosomes depends on selforganizing lipid and cargo domains [34]. Subsequently, cytoplasmic molecules such as proteins, lipids, and RNAs are encapsulated into the lumen and accumulated within the late endosome, thus forming multivesicular bodies (MVBs) [35]. The endoplasmic reticulum and Golgi complex are involved in the process. Partial MVBs fuse with the plasma membrane through cytoskeletal and microtubule network of the cell, ultimately releasing their vesicles into the extracellular space as exosomes, while others are transported to lysosomes for degradation through fusing with autophagosomes or not [36]. Compared with the degradative MVBs, the secreted MVBs contain more of ceramides [37, 38]. It has been reported that the different fates of MVBs may be related to the simultaneous existence of subpopulations in cells [19]. Since the endosome pathway is involved in exosome formation and release, proteins such as tetraspanins (CD9, CD63, and CD81), flotillin, Alix, and TSG101 are used as exosomal markers [19]. Additionally, exosomes are characterized by their high concentration of lipid raft components, such as ceramide and sphingomyelin [39, 40].

Although the process of exosome release remains elusive, it is widely accepted that Rab GTPases, soluble Nethylmaleimide-sensitive factor attachment protein receptors (SNAREs), and cytoskeleton are involved in the regulation process [41]. Rab GTPase proteins are involved in transferring vesicles between intracellular compartments and regulation of MVB fusion with plasma membrane for exosome release [42, 43]. For example, Rab27 is able to alter MVB morphology and dock to the plasma membrane. Rab35 is located on the surface of oligodendroglia cells and regulate the docking of endocytic vesicles and plasma membrane [42, 44]. The cytoskeleton exhibit significant polarity distribution inside the cells, allowing variation in the distribution of MVBs. Targeting actin polymerization may indirectly promote exosome secretion [24]. Soluble N-ethylmaleimidesensitive factor attachment protein receptors (SNAREs) are considered as central catalysts of intracellular membrane fusion [45]. SNARE complex facilitates fusion of two opposing membranes in a zipper-like manner [46].

It has been reported that endocytosis is the primary pathway for exosome uptake. In addition, exosomes can deliver cargo to recipient cells through direct membrane fusion and receptor-ligand binding [47]. The steps of exosome uptake mainly include targeting, entry, and delivery of content [24]. In particular, exosome uptake may be affected by crucial factors such as temperature and size distribution. Low temperature induces proteolytic cleavage of exosomal proteins thereby inhibiting the release of exosomes [48]. Smaller exosomes are more easily taken up by cells. Moreover, tetraspanin membrane proteins and intercellular adhesion molecule (ICAM1) are considered to promote the uptake of exosomes. Of note, the currently known biogenesis pathways are not specific for exosomes and not suitable for all cell types yet [24]. 


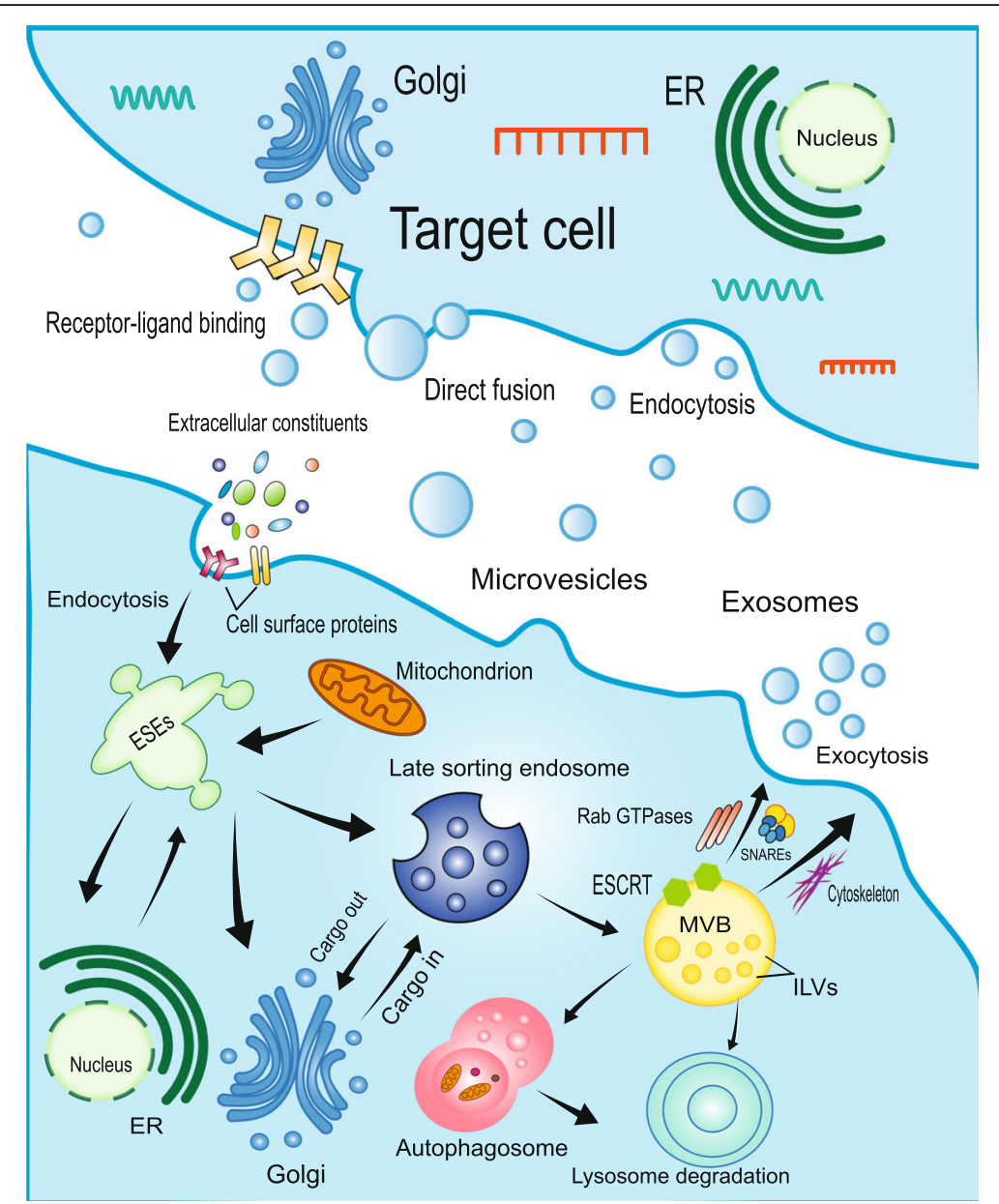

Fig. 1 The mechanism of exosome biogenesis, secretion, and uptake. Microvesicles are released through plasma membrane budding. Extracellular constituents and cell surface proteins form the early sorting endosome (ESEs) through endocytosis along with plasma membrane budding inward. The endoplasmic reticulum (ER), Golgi, and mitochondria are involved in the maturation of ESEs through fusion. ESEs give rise to late sorting endosome and multivesicular bodies (MVBs) in succession. Partial MVBs release their vesicles into the extracellular space as exosomes. Others are transported to lysosomes for degradation through fusing with autophagosomes or not. The formation of ILVs is mainly controlled by endosomal sorting complex required for transport (ESCRT). Rab GTPases, SNAREs, and cytoskeleton are involved in the regulation process of exosome secretion. Exosomes can deliver cargo to recipient cells by three methods: endocytosis, direct membrane fusion, and receptor-ligand binding

\section{Role of exosomes in AD}

To date, the exact etiology of AD is not particularly clear. Amyloid cascade hypothesis plays dominant role in explaining the genesis and progression of AD [49]. However, accumulating evidence demonstrate that amyloid cascade hypothesis fail to explain the pathophysiological mechanism of $\mathrm{AD}$ completely, and tau hypothesis, mitochondrial cascade hypothesis, and neuroinflammation hypothesis are proposed successively $[50,51]$. It is worth noting that exosomes are involved in the process of $\mathrm{AD}$ [52].

Firstly, brain-derived exosomes in peripheral blood have shown great potential to be an ideal "liquid biopsy" for $\mathrm{AD}$ (Table 1). Exosomes derived from blood are characterized by low invasive diagnostic procedures with high sensitivity and specificity [61]. Clinical diagnosis of
AD depends on symptoms, neuropsychological testing, lumbar puncture, and neuroimaging [62, 63]. Intriguingly, brain-derived exosomes can penetrate the blood-brain barrier into the peripheral blood circulation, but the concentration is lower than that of cerebrospinal fluid. To overcome these limitations, investigators enrich brainderived exosomes from plasma through immunoprecipitation methods. In addition, several studies suggest that due to the overlapping levels of $A \beta 1-42, T$-tau, and $p$-tau181 in CSF, it cannot effectively distinguish AD patients from other types of dementia patients [64]. Intriguingly, a multiple center study confirms the correlation between the levels of AD-associated protein in CSF and blood [55]. In the previous researches, lysosomal and synaptic proteins levels of neuron-derived exosomes (NDEs) are useful for 
Table 1 Exosomes as AD biomarkers in discussed studies

\begin{tabular}{|c|c|c|c|c|c|}
\hline Source & $\begin{array}{l}\text { Body } \\
\text { fluid }\end{array}$ & Isolation methods & $\begin{array}{l}\text { Validation } \\
\text { techniques }\end{array}$ & Direction of protein change & Ref. \\
\hline Neuronal & Plasma & $\begin{array}{l}\text { EXOQ + anti-L1CAM } \\
\text { immunocapture }\end{array}$ & TEM, NTA & $\begin{array}{l}\text { ADC and AD: P-T181-tau, P-S396-tau, and AB1-42 } \uparrow, \text { NRGN, REST } \downarrow \text { compared to } \\
\text { CNC and stable MCl patients }\end{array}$ & [53] \\
\hline Neurally & $\begin{array}{l}\text { Plasma } \\
\text { or serum }\end{array}$ & $\begin{array}{l}\text { EXOQ + anti-NCAM } \\
\text { immunocapture }\end{array}$ & NTA & $\begin{array}{l}\text { AD: total Tau, P-T181-tau, P-S396-tau and A } A 1-42 \uparrow \text { compared to controls } \\
\text { FTD: P-T181-tau and A } 11-42 \uparrow \text { compared to controls }\end{array}$ & [54] \\
\hline Neuronal & $\begin{array}{l}\text { Plasma } \\
\text { or CSF }\end{array}$ & $\begin{array}{l}\text { EXOQ + anti-NCAM } \\
\text { immunocapture }\end{array}$ & TEM, WB & $\begin{array}{l}\text { AD: A } 342, \text { T-tau, and P-T181-tau } \uparrow \text { compared to aMCl and control groups } \\
\text { The level of each exosomal biomarker was highly correlated with that in CSF }\end{array}$ & [55] \\
\hline Neuronal & Plasma & $\begin{array}{l}\text { EXOQ + anti-L1CAM } \\
\text { immunocapture }\end{array}$ & $\begin{array}{l}\text { NTA, TEM, } \\
\text { WB }\end{array}$ & $\begin{array}{l}\text { AD and FTD: synaptophysin, synaptopodin, synaptotagmin-2, and neurogranin } \downarrow \\
\text { compared to controls } \\
\text { AD: GAP43, synapsin } 1 \downarrow \text { synaptotagmin, synaptophysin, and neurogranin were } \\
\text { correlated with MMSE or ADAS-cog }\end{array}$ & [56] \\
\hline Neurally & Plasma & $\begin{array}{l}\text { EXOQ + anti-L1CAM } \\
\text { immunocapture }\end{array}$ & NTA & $\begin{array}{l}\text { AD: cathepsin D, LAMP- } 1 \text {, ubiquitinylated proteins } \uparrow \text {, and HSP70 } \downarrow \text { compared to } \\
\text { controls and FTD }\end{array}$ & [57] \\
\hline Neuronal & Plasma & $\begin{array}{l}\text { EXOQ + anti-L1CAM } \\
\text { immunocapture }\end{array}$ & $\begin{array}{l}\text { NTA, TEM, } \\
\text { WB }\end{array}$ & $\begin{array}{l}\text { AD:NPTX2, NRXN2a, AMPA4, NLGN1 } \downarrow \\
\text { Preclinical period: NRXN2a, AMPA4, and NLGN1 } \downarrow \text { compared to controls }\end{array}$ & [58] \\
\hline Astrocyte & Plasma & $\begin{array}{l}\text { EXOQ + anti-ACSA-1 } \\
\text { immunocapture }\end{array}$ & $\begin{array}{l}\text { NTA, TEM, } \\
\text { WB }\end{array}$ & $\begin{array}{l}\text { AD: complement proteins, IL-6, TNF-a, IL-1 } \beta \uparrow \text {; complement regulatory proteins } \\
\text { (CD59, CD46, DAF), complement receptor type } 1 \downarrow \text { compared to controls }\end{array}$ & [59] \\
\hline Astrocyte & Plasma & $\begin{array}{l}\text { EXOQ + anti-ACSA-1 } \\
\text { immunocapture }\end{array}$ & NTA & $\begin{array}{l}\text { AD: BACE-1, (s)APP } \beta \uparrow, \text { GDNF } \downarrow \text { compared to controls } \\
\text { FTD: compared to controls } n \text {. } d \text {. }\end{array}$ & {$[60]$} \\
\hline \multicolumn{6}{|c|}{$\begin{array}{l}\uparrow \text { higher; } \downarrow \text { lower; } n \text {. } d \text {. no difference compared to control, EXOQ ExoQuick exosome precipitation solution, LICAM neural adhesion protein, TEM transmission } \\
\text { electron microscope, NTA Nanoparticle Tracking Analysis, MCI mild cognitive impairment, ADC MCI converting to AD, REST repressor element 1-silencing } \\
\text { transcription factor, NRGN neurogranin, ADAS-cog AD assessment scale-cognitive subscale, CNC cognitively normal controls, FTD frontotemporal dementia, } \\
\text { GAP43growth-associated protein 43, MMSE Mini-Mental State Examination, LAMP-1 lysosome-associated membrane protein } 1, H S P 70 \text { heat-shock protein } 70, A C S A-1 \\
\text { antihuman glutamine aspartate transporter, NPTX2 neuronal pentraxin } 2, N R X N 2 a \text { neurexin } 2 a, A M P A 4 \text { GluA4-containing glutamate, NLGN1 receptor and neuroligin } \\
1, T N F-a \text { tumor necrosis factor-a, DAF decay-accelerating factor, BACE-1 } \beta \text {-site amyloid precursor protein-cleaving enzyme 1, (s)APP soluble amyloid precursor } \\
\text { protein, GDNF glial-derived neurotrophic factor }\end{array}$} \\
\hline
\end{tabular}

the preclinical risk prediction of conversion from mild cognitive impairment (MCI) to dementia $[56,57]$. The reductions in NDE levels of functionally specialized synaptic proteins may reflect the severity of AD progression [58]. Furthermore, the levels of complement proteins in exosomes derived from astrocytes (ADEs) are apparently associated with stage of the disease [59]. Cargo proteins in plasma ADEs are significantly higher than those in NDEs, which may be a potential target for BACE-1 inhibitors [56]. Moreover, large cohort studies are needed to assess the diagnosis utility of exosomes, and standardized process for preparation and biomarker quantification is still greatly challenging [65].

Secondly, exosomes are considered as a potential vehicle for drug delivery in $\mathrm{AD}$. As a natural biological agent, exosomes possess homing capabilities to transport active molecules between cells with favorable biocompatibility, and transiently modulate functions of targeted cells [66]. It has reported that MSC-exos can interact with target cells through different mechanisms. For example, MSC-exos can directly bind to membrane receptors to internalize their contents in target cells. Moreover, MSC-exos are able to deliver biologically active substances into target cells by fusion with the plasma membrane. What is more, exosomes are able to cross the blood-brain barrier (BBB) easily to enhance intracranial drug concentration [67]. Compared with conventional approaches of administration, exosome delivery avoids some complications, including intracranial infection, nonspecific absorption, and drug toxicity [68]. Lipid bimolecular structure of exosomes contributes to improving transport efficiency and supporting the load of hydrophobic or hydrophilic drugs [69]. Moreover, exosomes are characterized by low immunogenicity and long circulating half-life, which can prevent "therapeutic cargo" from rapid degradation [68]. Previous studies indicate that exosomes can deliver drugs or siRNA to the brain of $\mathrm{AD}$ mice $[68,70]$. However, there are evidences which demonstrate that predominant localization of intravenously administered exosomes is in the spleen and liver, with lower signals in the brain [71]. In order to increase the concentration of intravenously administered exosomes, the surface of exosomes can be modified by connecting peptides. For example, exosomes from engineered dendritic cells expressing membrane protein Lamp2b can bind to neuron-specific Rabies virus glycoprotein (RVG) peptide. These results showed that the cognitive function of $\mathrm{AD}$ transgenic mice injected with engineered MSC-exos was significantly improved [72].

Additionally, exosomes are involved in the process of pathogenic protein clearance. Beta-amyloid peptide and tau, two symbolic pathological proteins in AD, have been suggested to be associated with the neuronal damage and death, leading to gradual decline in memory and cognitive impairment [73]. Previous studies suggest that exosomes can reduce the deposition of $A \beta$ in different ways. For example, NDEs facilitate the conversion of $A \beta$ 
to nontoxic amyloid fibrils via driving conformational changes [74]. Inhibiting neutral sphingomyelinase 2 (nSMase2) contribute to reducing the conversion of sphingomyelin to ceramide and ultimately reduce the deposition of amyloid plaque [75]. Glycosphingolipids (GSLs) on the surface of exosomes can bind to $A \beta$, accelerating the clearance of amyloid depositions and reducing synaptic toxicity [76]. Notably, the evidence demonstrate that exosomes are not only involved in accelerating clearance of aggregated proteins, but also contribute to propagation of pathogenic proteins [77]. The propagation of pathogenic protein in $\mathrm{AD}$ is along neuroanatomically connected areas of the brain, which is considered to occur in a prion-like manner [78]. However, the transmission mechanism of the pathogenic protein is still controversial and further research is needed.

Finally, exosomes play a role in promoting neurogenesis and reducing cognitive impairment. However, the specific cellular and molecular mechanisms of these processes are still unclear. It has been reported that NDEs are able to regulate the number of AMPA receptors for glutamate transmission or induce synaptic pruning by the overexpression complement component 3 of microglia cells, indicating that NDEs are involved in the process of synaptic plasticity. Additionally, neuronal EVs are involved in the regulation of miRNA content and neuronal excitability $[79,80]$. Several studies have reported the existence of exosomes of non-neuronal cell origin. In the state of oxygen and glucose deprivation, oligodendrocyte-derived EVs contribute to elevate neuronal viability via uptake by neurons. Additionally, oligodendrocyte-derived exosomes are involved in the regulation of oxidative stress and increment of firing rate of neurons [81]. Exosomes derived from microglial are confirmed to regulate synaptic activity and transmit neuroprotective substances between cells [82]. Microvesicles derived from microglial are involved in the process of upregulating synaptic activity by promoting ceramide and sphingosine production [83]. Moreover, the surface of ADEs which expressed a novel glycoprotein (Synapsin-1) facilitates neurite outgrowth in the state of oxidative stress [84], which is a benefit for the recovery of nerve impairment. Interestingly, it was reported that exosomes can restore nerve function by increasing nerve density and inhibiting oxidative stress damage, rather than generating new neurons [85].

\section{MSC-exos isolation, storage, and administration}

MSCs are a class of adult multipotent stromal cells with self-renewal capabilities. They can be isolated from a variety of sources, including bone marrow (BM-MSCs), adipose tissue (AD-MSCs), umbilical cord (UC-MSCs), amniotic fluid, placenta, and peripheral blood [86-91]. The International Society for Cellar Therapy defines that
MSCs should express the cell surface markers CD73, CD90, and CD105, but not hematopoietic and endothelial antigens (CD14 or CD11b, CD19 or CD79 $\alpha$, CD34, CD45, HLA-DR) [92]. As stem cells, MSCs contribute to differentiating into cell lineages of mesodermal origin (e.g., osteoblasts, chondrocytes, and adipocytes) through stimulation in vitro [93]. However, this issue is still controversial. Some studies indicate that MSCs are able to differentiate into other cell types, such as endothelial cells, neural cells, glial cells, cardiomyocytes, and hepatocytes [94-96]. Differences of cell sources, isolation protocols, and culture environment can affect the properties of MSCs (Table 2). In the previous research, autologous MSCs are different from those of healthy donors, which will influence the outcomes of treatment [97]. Compared with other cell types, MSCs are able to produce higher doses of exosomes. The production of exosomes is related to the proliferation rate of MSCs. The cell density and content of secreted growth factors in MSCs cultured with three-dimensional (3D) spheroid were more than those with traditional monolayer culture [98]. Unlike cell transplantation, exosomes do not need to be cultured to a suitable density before transplantation, which lays the foundation for the treatment of acute diseases [97].

Given the heterogeneity and complexity of exosomes, different isolation methods have been discovered (Table 3). (1) Ultracentrifugation (UC) is to obtain purified exosomes by repeated differential centrifugation, filtration, and washing, which was considered as the most widely used method in the current researches. However, membrane damage of exosomes may occur during centrifugation. Additionally, UC requires long time and expensive equipment support [120]. For further exosome purification, an additional density gradient step can be added on the basis of UC. However, the drawbacks of this method are low yields [121]. (2) Size-exclusion chromatography (SEC) is used to separate exosomes based on hydrodynamic volume. This process is filtered through a stationary-phase column of porous beads with approximately the same size as the particle of interest [122]. The characteristic of SEC is time-saving, low cost, and good repeatability, but the recovery rate and purity of exosomes are reduced. (3) Filtration is a separation method based on the molecular mass and size of particles. After the initial filtration, additional ultrafiltration and repeated washing processes are needed to remove the impurities. The advantage of filtration is it is simple, gentle, and time-saving. However, exosomes may cause morphological changes due to squeezing when passing through the filter membrane, resulting in a lower recovery rate [123]. (4) Immunoaffinity isolation methods are based on the specific antigen-antibody interactions to capture exosomes, such as coated magnetic bead immunoaffinity pull-down or filter paper chromatography 
Table 2 Overview the characteristics of the described exosome isolation methods

\begin{tabular}{|c|c|c|c|c|}
\hline Methods & Working principle & Advantages & Disadvantages & Ref. \\
\hline UC & $\begin{array}{l}\text { Differential } \\
\text { centrifugationbased on } \\
\text { density }\end{array}$ & $\begin{array}{l}\text { Reduced protein contamination } \\
\text { High purity }\end{array}$ & $\begin{array}{l}\text { Low yield, difficult to separate particles of similar } \\
\text { size, expensive equipment support }\end{array}$ & $\begin{array}{l}{[99-} \\
101]\end{array}$ \\
\hline $\begin{array}{l}\text { Density } \\
\text { gradient }\end{array}$ & $\begin{array}{l}\text { Based on density } \\
\text { additional steps after } \\
\text { centrifugation }\end{array}$ & High purity & Low yield, time-consuming & [102] \\
\hline SEC & $\begin{array}{l}\text { Based on hydrodynamic } \\
\text { radius }\end{array}$ & $\begin{array}{l}\text { Good reproducibility, rapid and mild } \\
\text { Reduced protein contamination }\end{array}$ & Low sample recovery & $\begin{array}{l}{[103,} \\
104]\end{array}$ \\
\hline Filtration & $\begin{array}{l}\text { Based on molecular mass } \\
\text { and size }\end{array}$ & Simple and time-saving & $\begin{array}{l}\text { Potential to alter structural integrity, low sample } \\
\text { recovery }\end{array}$ & $\begin{array}{l}{[105,} \\
106]\end{array}$ \\
\hline Immunoaffinity & Antibody capture & $\begin{array}{l}\text { High selectivity and purity, no need for } \\
\text { additional equipment support }\end{array}$ & High cost, nonspecific binding & [107] \\
\hline $\begin{array}{l}\text { Commercial } \\
\text { kits }\end{array}$ & Precipitation with chemicals & High yield & High protein contamination & $\begin{array}{l}{[53,} \\
58]\end{array}$ \\
\hline AF4 & Laminar flow & Classification of EV subtypes, efficiently & Low sample recovery and repeatability & [108] \\
\hline Nano-FCM & $\begin{array}{l}\text { High-resolution flow } \\
\text { cytometry }\end{array}$ & High-fidelity sorting & $\begin{array}{l}\text { Simultaneous detection of multiple EVs, } \\
\text { expensive equipment support }\end{array}$ & [109] \\
\hline Microfluidics & $\begin{array}{l}\text { Based on physical or } \\
\text { mechanical characteristics }\end{array}$ & $\begin{array}{l}\text { Low sample volumes, rapid and high } \\
\text { purity }\end{array}$ & $\begin{array}{l}\text { Not suitable for large sample processing, } \\
\text { expensive equipment support }\end{array}$ & [110] \\
\hline
\end{tabular}

UC ultracentrifugation, SEC size-exclusion chromatography, AF4 asymmetric flow field-flow fractionation, FCM flow cytometry

Table 3 Application of MSC-derived EVs in Alzheimer's disease

\begin{tabular}{|c|c|c|c|c|}
\hline Source & $\begin{array}{l}\text { Extraction } \\
\text { method }\end{array}$ & Administration scheme & Results & Ref. \\
\hline hucMSC & ExoQuick & $\begin{array}{l}\text { Male } 7 \text { months old ABPP/PS1 mice } 30 \mu \mathrm{g} / 100 \mu \mathrm{l} \text {, i.v., every } 2 \text { weeks, } \\
\text { four times }\end{array}$ & $\begin{array}{l}\text { Alleviate neuroinflammation and } A \beta \\
\text { deposition }\end{array}$ & [111] \\
\hline ADSCs & Ultracentrifuge & Co-culture N2a cells with ADSCs in serum-free medium for 2-3 days & $\begin{array}{l}\text { Carry active NEP } \\
\text { Decrease } A \beta \text { levels }\end{array}$ & [112] \\
\hline $\begin{array}{l}\text { RVG- } \\
\text { BM- } \\
\text { MSC }\end{array}$ & Ultracentrifuge & $\begin{array}{l}\text { 7-month-old APP/PS1 mice; B6C3-Tg } 5 \times 10^{11} / 100 \mu \text { l, i.v. monthly for } \\
4 \text { months }\end{array}$ & $\begin{array}{l}\text { Improve learning and memory capabilities } \\
\text { Reduce plaque deposition } \\
\text { Normalize inflammatory cytokine levels }\end{array}$ & {$[72]$} \\
\hline $\begin{array}{l}\text { BM- } \\
\text { MSC }\end{array}$ & Ultracentrifuge & APP/PS1 mice $100 \mu \mathrm{g} / 5 \mu \mathrm{l}$, i.c.v., once per 2 days for 2 weeks & $\begin{array}{l}\text { Alleviate iNOS expression } \\
\text { Improve cognitive behavior } \\
\text { Reduce synaptic impairment and LTP }\end{array}$ & [113] \\
\hline $\begin{array}{l}\text { PC-BM- } \\
\text { MSC }\end{array}$ & ExoQuick & 7-month-old APP/PS1 mice $150 \mu \mathrm{g} / 80 \mu \mathrm{l}$, i.v., biweekly for 4 months & $\begin{array}{l}\text { Improve learning and memory capabilities } \\
\text { Restore synaptic dysfunction } \\
\text { Regulate inflammatory responses }\end{array}$ & {$[114]$} \\
\hline hMSC & Ultracentrifuge & $\begin{array}{l}\text { hippocampal cells incubated with HMSC-EVs }\left(6 \times 10^{8} \text { particles }\right) \text { for } \\
22 \mathrm{~h} \text {, add } \mathrm{A} \beta \mathrm{O} \text { s }(500 \mathrm{nM}) \text { for } 2 \mathrm{~h}\end{array}$ & $\begin{array}{l}\text { Rescue oxidative stress } \\
\text { Block synapse damage } \\
\text { Carry active catalase }\end{array}$ & {$[115]$} \\
\hline $\begin{array}{l}\text { BM- } \\
\text { MSC }\end{array}$ & Ultracentrifuge & $\begin{array}{l}\text { Co-culture MSC-exo with hippocampal neurons in serum-free } \\
\text { medium for } 24 \mathrm{~h} \text {, add ABOs ( } 500 \mathrm{nM}) \text { for } 6 \mathrm{~h} / 24 \mathrm{~h}\end{array}$ & $\begin{array}{l}\text { Protect neurons against } A \beta O \text {-induced oxi- } \\
\text { dative stress and synapse damage }\end{array}$ & [116] \\
\hline ADSCs & $\begin{array}{l}\text { Ultracentrifuge } \\
+ \text { ExoQuick }\end{array}$ & $\begin{array}{l}\text { Incubate NSCs from TG2576 mice with ADSC-exo }(200 \mu \mathrm{g} / \mathrm{mL}) \text { for } \\
24 / 48 \mathrm{~h}\end{array}$ & Reduce $A \beta$ levels and neuronal apoptosis & [117] \\
\hline $\begin{array}{l}\text { BM- } \\
\text { MSC }\end{array}$ & Ultracentrifuge & 5-month-old APP/PS1 mice $22.4 \mu \mathrm{g} / 4 \mu \mathrm{L}$, i.c.v. & $\begin{array}{l}\text { Reduce } A \beta \text { burden and the amount of } \\
\text { dystrophic neurites } \\
\text { Carry neprilysin }\end{array}$ & [118] \\
\hline hUMSCs & Ultracentrifuge & $\begin{array}{l}\text { Nine-month-old male APP/PS1 mice } 2 \mathrm{mg} / \mathrm{ml} \text {, i.c.v., continuously at } \\
0.25 \mathrm{\mu L} / \mathrm{h} \text { for } 14 \text { days }\end{array}$ & $\begin{array}{l}\text { Reduce } A \beta \text { generation, inflammation and } \\
\text { oxidative stress } \\
\text { Inhibit microglia activity } \\
\text { Improve spatial learning and memory } \\
\text { function }\end{array}$ & [119] \\
\hline
\end{tabular}


[124]. The advantage of this method is specific purification. However, the antibodies may have weaknesses, such as short lifespan, nonspecific binding, and crossreactivity. (5) Commercial kits are popular in the current research, including ExoQuick ${ }^{\mathrm{rm}}$, Exo-Flow ${ }^{\mathrm{mm}}$, and Total Exosome Isolation Precipitation. The yield of exosomes isolated with commercial kits is substantial, but the protocols are complicated and the purity of exosomes is low $[124,125]$. (6) Nano-flow cytometry (Nano-FCM) has been proved to be efficient in the isolation and quantification of exosomes [126]. Compared with traditional flow cytometry, Nano-FCM could detect the particles below the size of $200 \mathrm{~nm}$. The disadvantages of FCM are the multiple nano-particles detected at the same time, resulting in high signal and inaccurate measurement [127, 128]. In addition, several emerging technologies are gradually being applied, such as microfluidic EV isolation techniques and asymmetric flow field-flow fractionation (AF4) [106]. Taken together, isolation methods with few separation steps will result in high yield but low purity of exosomes. To date, the standards for exosome isolation have not been unified. Therefore, we can combine multiple methods to improve the separation efficiency [129].

Several studies indicate that the storage temperature and freeze-thaw times are able to affect the therapeutic utility of exosomes. After comparing, researchers suggest that storage temperature at $-80^{\circ} \mathrm{C}$ is the most suitable condition for long-term preservation of exosomes [130]. Repeated freezing and thawing may not only cause inaccurate assessment of the size and quantity of exosomes, but also induce the loss of cargo. Therefore, the minimized freeze-thaw cycles will be beneficial to maintain the characteristics and functions of exosomes [131].

To date, the administration route and dosage of MSCexos are still inconclusive. Experimental results indicate that the route or schedule of administration may significantly influence the dosage of therapeutic MSC-exos [132]. In addition, further research is also needed to determine the frequency of administration based on the duration of exosomes in vivo. Of note, it has been shown that repetitive or sustained delivery of MSC-exos significantly enhances their biovailability and efficacy [133]. Importantly, the optimal therapeutic scheme should be comprehensively determined according to the clinical condition [132].

\section{Therapeutic properties of MSC-exos in AD}

MSC-derived microvesicles were initially proposed to promote cell proliferation and enhance anti-apoptotic ability of tubular epithelial cells in acute tubular injury model in 2009 [134]. Accumulating evidence demonstrate that MSC-exos possess the ability of modulating immunity, promoting $A \beta$ degradation, and ameliorating neurological impairments (Fig. 2). In this context, MSCexos are considered to be a potential option for the treatment of $\mathrm{AD}$ (Table 2).

\section{MSC-exos promote $A \beta$ degradation}

In the previous studies, $\beta$-amyloid is considered as the production of proteolytic cleavage of the amyloid precursor protein (APP) by $\beta$ - and $\gamma$-secretases [135]. A $\beta$ monomers are relatively nontoxic, while oligomers are the reverse. Actually, the production and degradation of $\mathrm{A} \beta$ is balanced in the normal brain, while the abnormal accumulation results in metabolic imbalance. Once the clearance capacity of lysosomes or glial cells is overloaded, the pathogenic protein will be released into extracellular space and propagate across different brain areas through the exosome pathway. Clearance of pathogenic proteins has been shown to be beneficial in the treatment of AD [136]. Neprilysin (NEP) and insulindegrading enzyme (IDE), zinc metallopeptidase, are related to $A \beta$ degradation in the brain [137]. In 2000, researchers injected radiolabeled synthetic $A \beta$ 1-42 peptide into rat hippocampus and observed that the brain-derived NEP was capable of proteolyzing peptide subsequently [138]. In NEP- or IDE-deficient mice, endogenous $A \beta$ levels were elevated in a gene dosedependent manner $[139,140]$. In the recent research, MSC-exos with NEP and IEP activity reduced the deposition of $\mathrm{A} \beta$ plaques of $\mathrm{AD}$ transgenic mice through intravenous injection $[111,112]$. Therefore, MSC-exos play an important role in the degradation of $A \beta$, reflecting potential of MSC-exos in the treatment of AD.

\section{Immunomodulatory effects of MSC-exos}

It is widely indicated that the pathogenesis of $\mathrm{AD}$ is closely related to the immune system. To our knowledge, classical neuroimmune cell-to-cell communication is interacted with membrane [79]. MSCs play an immunomodulatory role through low levels of class II major histocompatibility complex (MHC-II) and costimulatory molecules on the cell surface [141]. Of note, MSC-exos containing the immunologically active molecules can regulate the immune cells. For example, MSCexos contribute to inhibiting the proliferation and differentiation of lymphocytes [142]. Moreover, MSC-exos are involved in inducing lymphocytes to differentiate into an anti-inflammatory type. To our knowledge, MSC-exos are able to induce conversion of T helper type 1 (Th1) cells into T helper type 2 (Th2) cells, reduce potential of $\mathrm{T}$ cells to differentiate into interleukin 17-producing effector $\mathrm{T}$ cells (Th17), and elevate the expression of regulatory cells (Tregs) [143, 144]. Additionally, several studies have demonstrated that inflammatory cytokines and proteins contained in MSC-exos have immunomodulatory effects. 


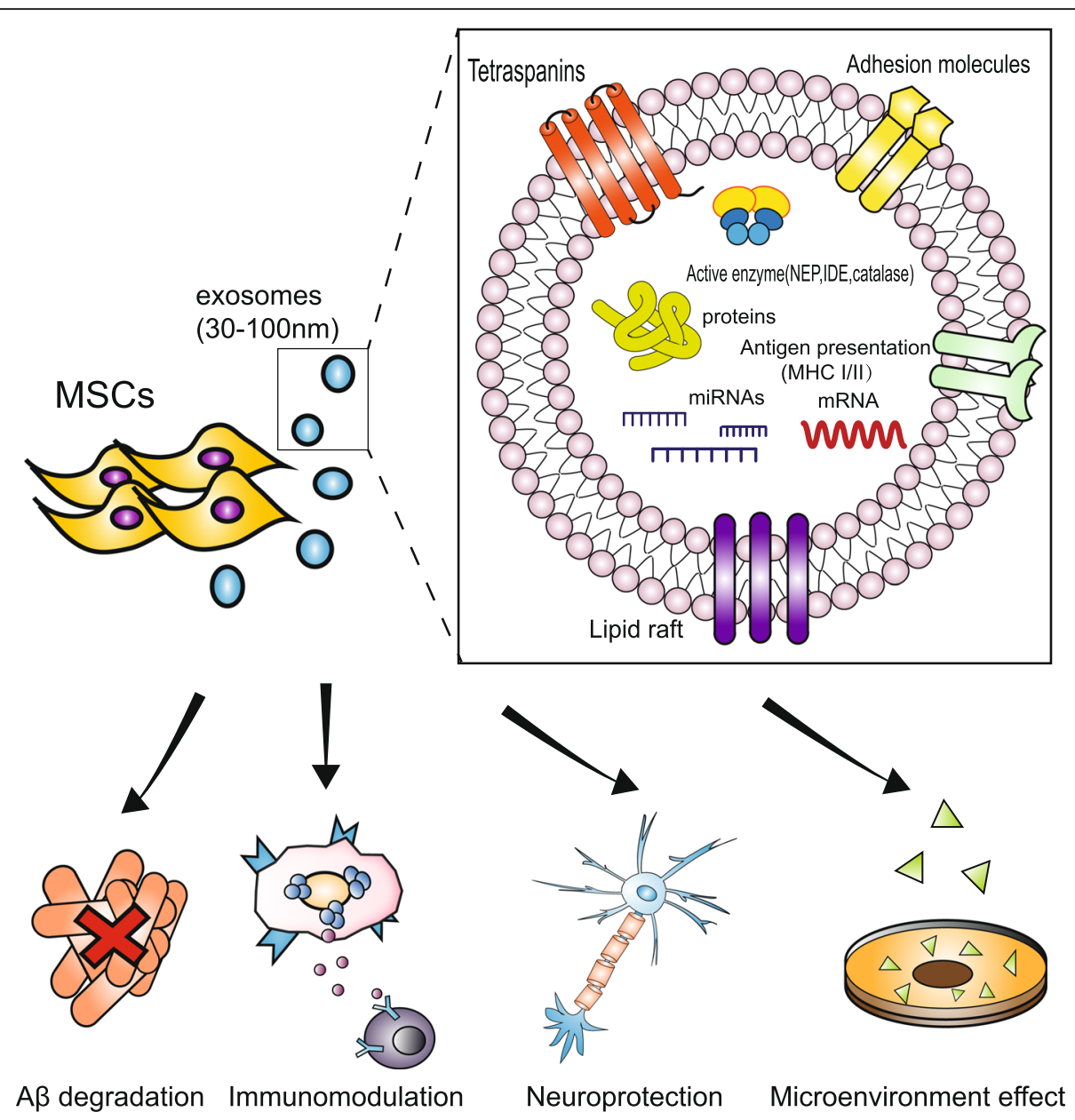

Fig. 2 The cargo and therapeutic role of MSC-exos in AD. MSC-exos are a subtype of extracellular microvesicles characterized by a lipid bilayer membrane structure with a diameter of 30-100 nm. Exosomes generally include active cargos such as proteins, lipids, and nucleic acids. In particular, MSC-exos carry AB degradation-related enzyme (NEP, IDE). The arrows show the therapeutic role of MSC-exOs in AD, including A degradation, immunomodulation, neuroprotection, and microenvironment effect

Neuroinflammation is emerging as a central pathological process in $\mathrm{AD}[145]$. Excessive accumulation of $\mathrm{A} \beta$ in the brain triggered the neuroinflammation process. MSC-exos contribute to immune regulation and neuroinflammation amelioration in pathological abnormal areas, as well as significantly improve the spatial learning ability and memory impairments in $\mathrm{AD}$ transgenic mice [72, 144]. Moreover, MSC-exos contribute to inducing antiinflammatory effects by the inhibition of activated microglia, reactive astrocytes, and the release of cytokine [146].

In addition, MSC-exos are able to suppress inflammatory response through regulating enzyme activity. $A \beta$ induce nitric oxide synthase (NOS) in glial cells and then release high levels of nitric oxide (NO). NO induces neurotoxicity via inhibition of mitochondrial respiration, resulting in neuronal cell death [147]. In this context, MSC-derived extracellular vesicles (EVs) reduce the expression of iNOS in vitro and alleviate the deficits of APP/PS1 mice in longterm potentiation (LTP) to CA1 synaptic [113].
Several previous studies suggested that MSC-exos affect post-transcriptional gene expression and ensue protein expression in the target cells via the delivery of miRNAs. miRNAs, small noncoding RNAs, play a key role in regulating several biological processes such as growth, inflammation, and angiogenesis. Exosomes containing miRNAs released by MSCs can inhibit the activity of immune cells and enable their phenotypic conversion into anti-inflammatory. For example, microglia plays the role of first innate immune defensive line in brain. When activated, microglia exhibit two different polarized phenotypes namely M1/M2 [97, 148]. In vivo and vitro models, elevating the levels of miR-124-3p in microglial exosomes, result in the inhibition of neuronal inflammation by promoting anti-inflammatory M2 polarization and contribute to alleviating neurodegeneration [98, 105]. In a previous study, dysfunctional miRNAs are related to $A D$ via the observation of altered miRNA expression profiles in AD brains [149]. The 
levels of miRNA-21 are significantly reduced in the status of chronic inflammation and apoptosis. However, MSC-exos contains high levels of miRNA-21, which contributes to reducing inflammation and apoptosis [150]. Furthermore, exosomes from preconditioned MSCs not only effectively increased the level of miR-21, but also inhibited NF- $\mathrm{kB}$ activation and STAT3 expression in APP/PS1 mice. Overexpression of miR-21 contributes to rescue memory deficits and regulate pathologic process [114]. In addition, it has been confirmed that MSC-exos containing miR-142-3p, miR-223$3 p$, and miR-126-3p regulate dendritic cell maturation and promote their anti-inflammatory potential in other disease models. MSC-exos can inhibit the expression of TRAF6 and IRAK1 via delivery of miRNA-146a to macrophages, resulting in the downregulated phosphorylation of NF- $\mathrm{kB}$ and reduction of inflammatory factors. Moreover, it is well known that some miRNAs contained in MSC-EVs are obviously related to their therapeutic properties. For example, miR148a, miR532-5p, and miR378 participate in angiogenesis, cellular transport, proteolysis, and apoptosis. miR-21, miR-17-92, and miR$133 \mathrm{~b}$ are linked to neural damage, and miR-145 is related to the processes of cellular differentiation [151].

\section{Neuroprotective effects of MSC-exos}

Synapse dysfunction, another pathologic hallmark, generally appears in the early stage of AD, which is directly related to cognitive impairment. As suggested by recent findings, hMSC-EVs protect hippocampal neurons via blocking oxidative stress and synapse damage exposed to amyloid beta oligomers (A $\beta O s$ ) [115]. Additionally, researchers found that the mechanisms of neuroprotection by MSC-derived EVs are related to containing the endogenous active antioxidant enzyme, catalase [116]. The expression levels of synaptic proteins are capable of reflecting the function of synapses to some extent. Synapsin 1 and PSD95 are synaptic protein involved in nerve signal transmission and maintaining synaptic integrity. The exosomes derived from hypoxiapreconditioned MSCs significantly enhance the expression of synaptic proteins (Synapsin 1 and PSD95) [114]. Neurite growth and synaptogenesis are controlled in terms of neuronal development. ADSC-derived exosomes decrease the levels of apoptotic proteins (such as p53, Bax, pro-caspase-3, and cleaved-caspase-3) and simultaneously downregulate the expression of antiapoptotic proteins in vivo and vitro AD models. Moreover, ADSC-derived exosomes were found to increase the neurite growth of neuronal stem cells (NSCs) from the transgenic mice TG2576 by measuring the length and number of neurites [117]. In addition, MSC-exos are capable of transferring miR-133b into astrocytes and neurons and promote the recovery of neural function
[152]. Taken together, MSC-exos play a potential role in promoting neurite outgrowth and suggest the possibility of clinical treatment in AD [118].

\section{MSC-exos are affected by extracellular environment}

Given different cell sources, the characters of exosomes vary according to content of cargos, which are affected by the physiological situation and extracellular environment [119]. Hence, it is essential to consider the efficacy of MSCexos with environment changes. To our knowledge, MSCs are capable of strong plasticity as stem cells. Several recent studies have assessed that pretreated MSCs in vitro affect the contents and biological activities of secreted exosomes. It was reported that exosomes obtained from hypoxiapreconditioned MSCs (PC-MSCs) are able to enhance the therapeutic effect in AD transgenic mice [114]. The advantages of pretreatment group are mainly reflected in improving learning and memory capabilities, alleviating $A \beta$ accumulation, increasing synaptic protein expression, and suppressing inflammatory response. In recent research, MSCs were pretreated with GW627368X (a prostaglandin E2 receptor 4 antagonist), which induced MSC-EVs containing anti-inflammatory cytokines and neuron-supporting proteins. The induced MSC-EVs suppress astrogliosis and microglia infiltration, restore BBB integrity, and elevate memory and learning ability in the hippocampus damage model [153]. Intriguingly, the abovementioned therapeutic effects failed to appear in MSC-EVs under conventional culture condition. Additionally, it is worth noting that MSCs likely modify the characteristics of exosomes in pathological conditions. In turn, there are studies which show that MSC-EVs contributed to altering cellular metabolic microenvironment through carrying biologically active components [154]. Therefore, the continuous optimization of MSC pretreatment methods, at least to some extent, may enhance the therapeutic potential of MSC-exos in AD.

\section{Clinical trials of MSC-exos in AD}

Despite the results of previous experiment are promising, few on-going or completed clinical studies have explored the potential role of MSC-exos in clinical trials [96]. After consulting the database, there is a clinical trial now listed at www.clinicaltrials.gov utilizing MSC-exos. Researchers from the Shanghai Jiao Tong University School of Medicine decide to evaluate the safety and effectiveness of MSC-exos in patients with mild to moderate dementia (NCT04388982). This clinical trial plans to recruit 9 patients to participate in the study. Patients will be given three doses of low, medium, and high $(5 \mu \mathrm{g}, 10 \mu \mathrm{g}, 20 \mu \mathrm{g})$ MSC-exos twice a week, respectively, for 12 weeks via nasal drip as planned. In the primary stage of trails, patients will be measured for the functions of liver or kidney and treatment-related adverse events. Cognitive function, quality of life, and neuroimaging will be evaluated during 
the secondary stage of trails. Although the clinical trials of MSC-exos in the treatment of AD have not yet been done, promising results have been confirmed in other diseases (NCT03562715, NCT04356300, and NCT04134676). It is encouraging that MSC-exos can ameliorate inflammation and improve kidney function of grade III-IV chronic kidney disease (CKD) patients in a phase II/III clinical pilot study. Of note, during the 1 year follow-up, no adverse events related to the administration of MSC-exos were found in subjects [155]. In addition, the therapeutic effects of MSC-exos after stroke have been explored in the clinical trials conducted at Isfahan University of Medical Sciences (NCT03384433). Subjects were given allogenic MSC-exos transfected by miR-124 via a stereotactic technique. During the 1-year follow-up, subjects have been monitored for treatment-related adverse events, such as brain edema, deteriorating stroke, stroke recurrences, and hemorrhagic transformation. This study was completed in December 2019 and the results are unannounced. Therefore, based on the experience of successful clinical trials in other diseases, the results of MSC-exos in AD clinical trials are promising.

\section{Advantages and challenges for MSC-exos in the application of AD therapy}

Accumulating evidence suggest that MSC-exos possess superior safety profile, anti-inflammatory effects, minimal immunogenicity, and low risks of tumor formation [99, 156, 157]. Unlike MSCs, exosomes cannot replicate, which contribute to avoiding uncontrolled division. This feature of exosomes greatly reduces the risk of tumor formation during the process of proliferation [151]. Exosomes can also avoid mutations and DNA damage caused by cell transplantation [158]. Due to nanometric size, MSC-exos reduce the possibility of vascular obstruction and cross blood-brain barrier easier [159]. Moreover, the surface of MSC-exos could be modified and exploited into engineered exosomes, which can bind the ligands with target specific cells and escape immune responses [129]. The low immunogenicity of MSC-exos makes allogeneic applications possible [160]. In addition, engineered exosomes can increase the drug concentration of target organs and achieve personalized treatment effects. From the production perspective, mesenchymal stem cells (MSCs) possess biological characteristics of multi-differentiation potential and are effortless to proliferate and store. In addition, MSCs can not only produce high quantities of exosomes, but also ensure that the composition does not change significantly, which are appropriate to large-scale production [161].

As a therapeutic agent, MSC-exos still face great challenges. The main reasons may be attributed to the following points. (1) The isolation, storage, and purification protocols of MSC-exos still need continuous majorization and standardization to enhance the comparability and reproducibility. Since the conventional isolated methods mainly depend on density and size, some substances (lipoproteins, virus, etc.) may overlap with their characteristics, resulting in incomplete removal. Clinical applications depend on time-saving, low-cost, and convenient methods, but the existing separation methods obviously do not meet these conditions. In addition, in order to promote the development of effective biomarkers for exosomes, sensitive, accurate, and rapid quantitative methods are essential. (2) The therapeutic effects of MSC-exos in promoting neurite growth may vary depending on the source of MSCs [162]. However, due to the significant differences in the route of administration, dosage, separation protocols, and disease model, it is difficult to determine the specific source of MSC-exos with higher therapeutic potential. (3) Some detrimental cytokines of MSCs are secreted through paracrine effects, suggesting that it is essential to clarify the contents of exosomes and eliminate interference from unknown secretory factors. (4) Several critical technological issues have not yet been resolved, such as side effect of drugs, optimal dosage, and route of administration [163]. Due to the complex biological composition of exosomes, the difference between exosomes and single medication should be considered in the application process [160]. More experimental works are needed to be carried out before extensive clinical trials. Determining the specific therapeutic molecules of MSC-exos is worth noting in further research [132]. (5) The value of exosome as delivery vehicles required to be fully evaluated and directly compared with existing viral vectors and biosynthetic vectors [160].

\section{Conclusion}

Although much effort has been invested in $\mathrm{AD}$, the achievements seem to be unsatisfactory [164]. The previous works in $\mathrm{AD}$ therapeutics focused on the amyloid hypothesis. Unfortunately, almost all phase III clinical trials ended in failure, which suggest that other existing important pathological mechanisms are involved in the cause of AD [165]. As a novel cell-free therapeutic agent, MSC-exos have unparalleled advantages over cell-based therapy, which are considered to be a promising alternative in the therapy of AD.

\footnotetext{
Abbreviations

AD: Alzheimer's disease; MSC-exos: Mesenchymal stem cell-derived exosomes; FDA: Food and Drug Administration; ChEls: Cholinesterase inhibitors; BM: Bone marrow; AD-MSCs: Adipose tissue-derived mesenchymal stem cells; UC-MSCs: Umbilical cord mesenchymal stem cells; BDNF: Brain-derived neurotrophic factor; VEGF: Vascular endothelial growth factor; NGF: Nerve growth factor; EVs: Extracellular vesicles; ESEs: Early sorting endosome; ILVs: Intraluminal vesicles; ESCRT: Endosomal sorting complex required for transport; HSPs: Heat shock proteins; MCl: Mild cognitive impairment; MVBs: Multivesicular bodies; A $\beta$ : $\beta$-amyloid; ADEs: Exosomes derived from astrocytes; NFT: Neurofibrillary tangles; NDEs: Neuron-derived exosomes; BBB: Blood-brain barrier; RVG: Rabies virus glycoprotein; SNAREs: Soluble N-
} 
ethylmaleimide-sensitive factor attachment protein receptors; GSLs: Glycosphingolipids; nSMase2: Neutral sphingomyelinase 2; MAPS: Misfolding-associated protein secretion; NEP: Neprilysin; IDE: Insulindegrading enzyme; ADSCs: Human adipose tissue-derived mesenchymal stem cells; MHC-II: Class II major histocompatibility complex; Th1: T helper type 1; Th2: T helper type 2; Th17: Interleukin 17-producing effector T cells; PBMCs: Peripheral blood mononuclear cells; iNOS: Inducible nitric oxide synthase; UC: Ultracentrifugation; NOS: Nitric oxide synthase; FCM: Flow cytometry; LTP: Long-term potentiation; SEC: Size-exclusion chromatography; AF4: Asymmetric flow field-flow fractionation; APP: Amyloid precursor protein; PC: Preconditioned; CKD: Chronic kidney disease; eGFR: Estimated glomerular filtration rate; UACR: Urinary albumin creatinine

\section{Acknowledgements}

This work was supported by Department of Geriatrics, Tianjin Medical University General Hospital, Tianjin, China, and Tianjin Neurological Institute.

\section{Authors' contributions}

$Z Y$ and MG contributed to collecting and collating the data.MG wrote the manuscript.MG, ZY, and FC participated in the critical revision of the manuscript for important intellectual content. PL provided guidance on the coordination of authors and reviewed the manuscript. All authors reviewed and approved the final manuscript.

\section{Funding}

This work was supported by Grants 81772060 from the National Natural Science Foundation of China.

\section{Availability of data and materials}

Data sharing is not applicable to this article as no datasets were generated or analyzed during the current study.

\section{Ethics approval and consent to participate}

Not applicable.

\section{Consent for publication}

Not applicable.

\section{Competing interests}

The authors declare no competing interests.

\section{Author details}

'Department of Geriatrics, Tianjin Medical University General Hospital, Tianjin China. ${ }^{2}$ Tianjin Geriatrics Institute, Tianjin Medical University General Hospital, Tianjin, China. ${ }^{3}$ Tianjin Neurological Institute, Tianjin, China.

\section{Received: 26 May 2020 Accepted: 20 August 2020}

Published online: 14 September 2020

\section{References}

1. 2020 Alzheimer's disease facts and figures. Alzheimer's Dementia; 2020. https://doi.org/10.1002/alz.12068.

2. Jia L, Quan M, Fu Y, Zhao T, Li Y, Wei C, et al. Dementia in China: epidemiology, clinical management, and research advances. Lancet Neurol. 2020;19(1):81-92.

3. Joe E, Ringman JM. Cognitive symptoms of Alzheimer's disease: clinical management and prevention. Bmj. 2019;367:16217.

4. Ising C, Heneka MT. Functional and structural damage of neurons by innate immune mechanisms during neurodegeneration. Cell Death Dis. 2018;9(2):120.

5. Tarawneh R, Holtzman DM. The clinical problem of symptomatic Alzheimer disease and mild cognitive impairment. Cold Spring Harb Perspect Med. 2012:2(5):a006148.

6. Tang-Wai DF, Graff-Radford NR, Boeve BF, Dickson DW, Parisi JE, Crook R, et al. Clinical, genetic, and neuropathologic characteristics of posterior cortical atrophy. Neurology. 2004;63(7):1168-74.

7. Long JM, Holtzman DM. Alzheimer disease: an update on pathobiology and treatment strategies. Cell. 2019:179(2):312-39.

8. Yuan O, Lin C, Wagner J, Archard JA, Deng P, Halmai J, et al. Exosomes derived from human primed Mesenchymal stem cells induce mitosis and potentiate growth factor secretion. Stem Cells Dev. 2019;28(6):398-409.
9. Deng P, Anderson JD, Yu AS, Annett G, Fink KD, Nolta JA. Engineered BDNF producing cells as a potential treatment for neurologic disease. Expert Opin Biol Ther. 2016;16(8):1025-33.

10. Showalter MR, Wancewicz B, Fiehn O, Archard JA, Clayton S, Wagner J, et al. Primed mesenchymal stem cells package exosomes with metabolites associated with immunomodulation. Biochem Biophys Res Commun. 2019;512(4):729-35.

11. Park BW, Jung SH, Das S, Lee $S M$, Park JH, Kim H, et al. In vivo priming of human mesenchymal stem cells with hepatocyte growth factor-engineered mesenchymal stem cells promotes therapeutic potential for cardiac repair. Sci Adv. 2020;6(13):eaay6994.

12. Park HH, Lee S, Yu Y, Yoo SM, Baek SY, Jung N, et al. TGF-beta secreted by human umbilical cord blood-derived mesenchymal stem cells ameliorates atopic dermatitis by inhibiting secretion of TNF-alpha and lgE. Stem Cells. 2020; https://pubmed.ncbi.nlm.nih.gov/32277785/.

13. Ge X, Han Z, Chen F, Wang H, Zhang B, Jiang R, et al. MiR-21 alleviates secondary blood-brain barrier damage after traumatic brain injury in rats. Brain Res. 2015;1603:150-7.

14. Zhang F, Wang C, Wen X, Chen Y, Mao R, Cui D, et al. Mesenchymal stem cells alleviate rat diabetic nephropathy by suppressing CD103(+) DCsmediated CD8(+) T cell responses. J Cell Mol Med. 2020;24(10):5817-31.

15. Deng K, Lin DL, Hanzlicek B, Balog B, Penn MS, Kiedrowski MJ, et al. Mesenchymal stem cells and their secretome partially restore nerve and urethral function in a dual muscle and nerve injury stress urinary incontinence model. Am J Physiol Ren Physiol. 2015;308(2):F92-F100.

16. Yao $Y$, Huang J, Geng Y, Qian H, Wang F, Liu X, et al. Paracrine action of mesenchymal stem cells revealed by single cell gene profiling in infarcted murine hearts. PLoS One. 2015;10(6):e0129164

17. Witwer KW, Van Balkom BWM, Bruno S, Choo A, Dominici M, Gimona M, et al. Defining mesenchymal stromal cell (MSC)-derived small extracellular vesicles for therapeutic applications. J Extracell Vesicles. 2019;8(1):1609206.

18. Lai RC, Arslan F, Lee MM, Sze NS, Choo A, Chen TS, et al. Exosome secreted by MSC reduces myocardial ischemia/reperfusion injury. Stem Cell Res. 2010;4(3):214-22.

19. Colombo M, Raposo G, Thery C. Biogenesis, secretion, and intercellular interactions of exosomes and other extracellular vesicles. Annu Rev Cell Dev Biol. 2014;30:255-89.

20. Cocozza F, Grisard E, Martin-Jaular L, Mathieu M, Thery C. SnapShot: Extracellular Vesicles. Cell. 2020;182(1):262-e1.

21. Anderson HC. Vesicles associated with calcification in the matrix of epiphyseal cartilage. J Cell Biol. 1969;41(1):59-72.

22. Wolf $P$. The nature and significance of platelet products in human plasma. Br J Haematol. 1967;13(3):269-88.

23. Pan BT, Johnstone RM. Fate of the transferrin receptor during maturation of sheep reticulocytes in vitro: selective externalization of the receptor. Cell. 1983:33(3):967-78.

24. Mathieu M, Martin-Jaular L, Lavieu G, Thery C. Specificities of secretion and uptake of exosomes and other extracellular vesicles for cell-to-cell communication. Nat Cell Biol. 2019;21(1):9-17.

25. Stremersch S, De Smedt SC, Raemdonck K. Therapeutic and diagnostic applications of extracellular vesicles. J Control Release. 2016;244(Pt B):167-83.

26. Badhwar A, Haqqani AS. Biomarker potential of brain-secreted extracellular vesicles in blood in Alzheimer's disease. Alzheimers Dement (Amst). 2020; 12(1):e12001.

27. Lener T, Gimona M, Aigner L, Borger V, Buzas E, Camussi G, et al. Applying extracellular vesicles based therapeutics in clinical trials - an ISEV position paper. J Extracell Vesicles. 2015;4:30087.

28. Chaput N, Schartz NE, Andre F, Taieb J, Novault S, Bonnaventure P, et al. Exosomes as potent cell-free peptide-based vaccine. II. Exosomes in CpG adjuvants efficiently prime naive Tc1 lymphocytes leading to tumor rejection. J Immunol. 2004;172(4):2137-46.

29. Abels ER, Breakefield XO. Introduction to extracellular vesicles: biogenesis, RNA cargo selection, content, release, and uptake. Cell Mol Neurobiol. 2016; 36(3):301-12.

30. Hurley JH. ESCRTs are everywhere. EMBO J. 2015;34(19):2398-407.

31. Hanson PI, Cashikar A. Multivesicular body morphogenesis. Annu Rev Cell Dev Biol. 2012;28:337-62

32. Futter CE, Collinson LM, Backer JM, Hopkins CR. Human VPS34 is required for internal vesicle formation within multivesicular endosomes. I Cell Biol. 2001;155(7):1251-64

33. Juan T, Furthauer M. Biogenesis and function of ESCRT-dependent extracellular vesicles. Semin Cell Dev Biol. 2018;74:66-77. 
34. Yue B, Yang H, Wang J, Ru W, Wu J, Huang Y, et al. Exosome biogenesis, secretion and function of exosomal miRNAs in skeletal muscle myogenesis. Cell Prolif. 2020;53(7):e12857.

35. Harding C, Heuser J, Stahl P. Receptor-mediated endocytosis of transferrin and recycling of the transferrin receptor in rat reticulocytes. J Cell Biol. 1983; 97(2):329-39.

36. Kalluri R, LeBleu VS. The biology, function, and biomedical applications of exosomes. Science. 2020;367(6478):eaau6977.

37. Janas AM, Sapon K, Janas T, Stowell MH, Janas T. Exosomes and other extracellular vesicles in neural cells and neurodegenerative diseases. Biochim Biophys Acta. 2016;1858(6):1139-51.

38. Morelli AE, Larregina AT, Shufesky WJ, Sullivan ML, Stolz DB, Papworth GD, et al. Endocytosis, intracellular sorting, and processing of exosomes by dendritic cells. Blood. 2004;104(10):3257-66.

39. Bianco F, Perrotta C, Novellino L, Francolini M, Riganti L, Menna E, et al. Acid sphingomyelinase activity triggers microparticle release from glial cells. EMBO J. 2009;28(8):1043-54.

40. Trajkovic K, Hsu C, Chiantia S, Rajendran L, Wenzel D, Wieland F, et al. Ceramide triggers budding of exosome vesicles into multivesicular endosomes. Science. 2008;319(5867):1244-7.

41. Hessvik NP, Llorente A. Current knowledge on exosome biogenesis and release. Cell Mol Life Sci. 2018;75(2):193-208.

42. Hsu C, Morohashi Y, Yoshimura S, Manrique-Hoyos N, Jung S, Lauterbach MA, et al. Regulation of exosome secretion by Rab35 and its GTPaseactivating proteins TBC1D10A-C. J Cell Biol. 2010;189(2):223-32.

43. Ostrowski M, Carmo NB, Krumeich S, Fanget I, Raposo G, Savina A, et al Rab27a and Rab27b control different steps of the exosome secretion pathway. Nat Cell Biol. 2010;12(1):19-30 sup pp 1-13.

44. Fukuda M. Rab27 effectors, pleiotropic regulators in secretory pathways. Traffic. 2013:14(9):949-63.

45. Dingjan I, Linders PTA, Verboogen DRJ, Revelo NH, Ter Beest M, van den Bogaart G. Endosomal and Phagosomal SNAREs. Physiol Rev. 2018:98(3):1465-92.

46. Wang $T$, Li L, Hong W. SNARE proteins in membrane trafficking. Traffic. 2017:18(12):767-75.

47. He C, Zheng S, Luo Y, Wang B. Exosome theranostics: biology and translational medicine. Theranostics. 2018;8(1):237-55.

48. Clayton A, Turkes A, Dewitt S, Steadman R, Mason MD, Hallett MB. Adhesion and signaling by B cell-derived exosomes: the role of integrins. FASEB J. 2004;18(9):977-9.

49. Daly T, Houot M, Barberousse A, Agid Y, Epelbaum S. Amyloid-beta in Alzheimer's disease: a study of citation practices of the amyloid cascade hypothesis between 1992 and 2019. J Alzheimers Dis. 2020;74(4):1309-17.

50. Swerdlow RH. Mitochondria and mitochondrial cascades in Alzheimer's disease. J Alzheimers Dis. 2018;62(3):1403-16.

51. Shen Y, Ye B, Chen P, Wang Q, Fan C, Shu Y, et al. Cognitive decline, dementia. Alzheimers Dis Presbycusis. 2018;12:394.

52. Fevrier B, Vilette D, Archer F, Loew D, Faigle W, Vidal M, et al. Cells release prions in association with exosomes. Proc Natl Acad Sci U S A. 2004;101(26):9683-8.

53. Winston CN, Goetzl EJ, Akers JC, Carter BS, Rockenstein EM, Galasko D, et al. Prediction of conversion from mild cognitive impairment to dementia with neuronally derived blood exosome protein profile. Alzheimers Dement. 2016:3:63-72.

54. Fiandaca MS, Kapogiannis D, Mapstone M, Boxer A, Eitan E, Schwartz JB, et al. Identification of preclinical Alzheimer's disease by a profile of pathogenic proteins in neurally derived blood exosomes: a case-control study. Alzheimers Dement. 2015;11(6):600-7. e1.

55. Jia L, Qiu Q, Zhang H, Chu L, Du Y, Zhang J, et al. Concordance between the assessment of Abeta42, T-tau, and P-T181-tau in peripheral blood neuronal-derived exosomes and cerebrospinal fluid. Alzheimer's. Dementia. 2019;15(8):1071-80.

56. Goetzl EJ, Kapogiannis D, Schwartz JB, Lobach IV, Goetzl L, Abner EL, et al. Decreased synaptic proteins in neuronal exosomes of frontotemporal dementia and Alzheimer's disease. FASEB J. 2016:30(12):4141-8.

57. Goetzl EJ, Boxer A, Schwartz JB, Abner EL, Petersen RC, Miller BL, et al. Altered lysosomal proteins in neural-derived plasma exosomes in preclinical Alzheimer disease. Neurology. 2015;85(1):40-7.

58. Goetzl EJ, Abner EL, Jicha GA, Kapogiannis D, Schwartz JB. Declining levels of functionally specialized synaptic proteins in plasma neuronal exosomes with progression of Alzheimer's disease. FASEB J. 2018;32(2):888-93.

59. Goetzl EJ, Schwartz JB, Abner EL, Jicha GA, Kapogiannis D. High complement levels in astrocyte-derived exosomes of Alzheimer disease. Ann Neurol. 2018;83(3):544-52.
60. Goetzl EJ, Mustapic M, Kapogiannis D, Eitan E, Lobach IV, Goetzl L, et al. Cargo proteins of plasma astrocyte-derived exosomes in Alzheimer's disease. FASEB J. 2016;30(11):3853-9.

61. Eren E, Hunt JFV, Shardell M, Chawla S, Tran J, Gu J, et al. Extracellular vesicle biomarkers of Alzheimer's disease associated with sub-clinical cognitive decline in late middle age. Alzheimers Dement. 2020; https:// pubmed.ncbi.nlm.nih.gov/32588967/.

62. Fagan AM, Mintun MA, Mach RH, Lee SY, Dence CS, Shah AR, et al. Inverse relation between in vivo amyloid imaging load and cerebrospinal fluid Abeta42 in humans. Ann Neurol. 2006;59(3):512-9.

63. Lowe VJ, Lundt ES, Albertson SM, Przybelski SA, Senjem ML, Parisi JE, et al. Neuroimaging correlates with neuropathologic schemes in neurodegenerative disease. Alzheimers Dement. 2019:15(7):927-39.

64. Blennow K, Hampel H. CSF markers for incipient Alzheimer's disease. Lancet Neurol. 2003;2(10):605-13.

65. Lee S, Mankhong S, Kang JH. Extracellular vesicle as a source of Alzheimer's biomarkers: opportunities and challenges. Int J Mol Sci. 2019;20(7).

66. Iranifar E, Seresht BM, Momeni F, Fadaei E, Mehr MH, Ebrahimi Z, et al. Exosomes and microRNAs: new potential therapeutic candidates in Alzheimer disease therapy. J Cell Physiol. 2019;234(3):2296-305.

67. Qu M, Lin Q, Huang L, Fu Y, Wang L, He S, et al. Dopamine-loaded blood exosomes targeted to brain for better treatment of Parkinson's disease. J Control Release. 2018;287:156-66.

68. Wang $H$, Sui $H$, Zheng $Y$, Jiang $Y$, Shi $Y$, Liang J, et al. Curcumin-primed exosomes potently ameliorate cognitive function in AD mice by inhibiting hyperphosphorylation of the Tau protein through the AKT/GSK-3beta pathway. Nanoscale. 2019;11(15):7481-96.

69. Kim MS, Haney MJ, Zhao Y, Yuan D, Deygen I, Klyachko NL, et al. Engineering macrophage-derived exosomes for targeted paclitaxel delivery to pulmonary metastases: in vitro and in vivo evaluations. Nanomedicine. 2018;14(1):195-204.

70. Alvarez-Erviti L, Seow Y, Yin H, Betts C, Lakhal S, Wood MJ. Delivery of siRNA to the mouse brain by systemic injection of targeted exosomes. Nat Biotechnol. 2011:29(4):341-5.

71. Lai CP, Mardini O, Ericsson M, Prabhakar S, Maguire C, Chen JW, et al. Dynamic biodistribution of extracellular vesicles in vivo using a multimodal imaging reporter. ACS Nano. 2014;8(1):483-94.

72. Cui GH, Guo HD, Li H, Zhai Y, Gong ZB, Wu J, et al. RVG-modified exosomes derived from mesenchymal stem cells rescue memory deficits by regulating inflammatory responses in a mouse model of Alzheimer's disease. Immun Ageing. 2019;16:10.

73. DeLeo AM, Ikezu T. Extracellular vesicle biology in Alzheimer's disease and related Tauopathy. J Neurolmmune Pharmacol. 2018;13(3):292-308.

74. Yuyama K, Sun H, Mitsutake S, Igarashi Y. Sphingolipid-modulated exosome secretion promotes clearance of amyloid-beta by microglia. J Biol Chem. 2012;287(14):10977-89.

75. Dinkins MB, Dasgupta S, Wang G, Zhu G, Bieberich E. Exosome reduction in vivo is associated with lower amyloid plaque load in the 5XFAD mouse model of Alzheimer's disease. Neurobiol Aging. 2014:35(8):1792-800.

76. Yuyama K, Sun H, Sakai S, Mitsutake S, Okada M, Tahara H, et al. Decreased amyloid-beta pathologies by intracerebral loading of glycosphingolipidenriched exosomes in Alzheimer model mice. J Biol Chem. 2014;289(35): 24488-98.

77. Xiao T, Zhang W, Jiao B, Pan CZ, Liu X, Shen L. The role of exosomes in the pathogenesis of Alzheimer's disease. Transl Neurodegener. 2017:6:3.

78. Puangmalai N, Bhatt N, Montalbano M, Sengupta U, Gaikwad S, Ventura F, et al. Internalization mechanisms of brain-derived tau oligomers from patients with Alzheimer's disease, progressive supranuclear palsy and dementia with Lewy bodies. Cell Death Dis. 2020;11(5):314.

79. Delpech JC, Herron S, Botros MB, Ikezu T. Neuroimmune crosstalk through extracellular vesicles in health and disease. Trends Neurosci. 2019:42(5):361-72

80. Bahrini I, Song JH, Diez D, Hanayama R. Neuronal exosomes facilitate synaptic pruning by up-regulating complement factors in microglia. Sci Rep. 2015;5:7989.

81. Fröhlich D, Kuo WP, Frühbeis C, Sun J-J, Zehendner CM, Luhmann HJ, et al, Multifaceted effects of oligodendroglial exosomes on neurons: impact on neuronal firing rate, signal transduction and gene regulation. Philos Trans $\mathrm{R}$ Soc Lond Ser B Biol Sci. 2014;369(1652):20130510.

82. Paolicelli RC, Bergamini G, Rajendran L. Cell-to-cell communication by extracellular vesicles: focus on microglia. Neuroscience. 2019;405:148-57. 
83. Antonucci F, Turola E, Riganti L, Caleo M, Gabrielli M, Perrotta C, et al. Microvesicles released from microglia stimulate synaptic activity via enhanced sphingolipid metabolism. EMBO J. 2012;31(5):1231-40.

84. Wang S, Cesca F, Loers G, Schweizer M, Buck F, Benfenati F, et al. Synapsin I is an oligomannose-carrying glycoprotein, acts as an oligomannose-binding lectin, and promotes neurite outgrowth and neuronal survival when released via glia-derived exosomes. J Neurosci. 2011;31(20):7275-90.

85. Nakano M, Nagaishi K, Konari N, Saito Y, Chikenji T, Mizue Y, et al. Bone marrow-derived mesenchymal stem cells improve diabetes-induced cognitive impairment by exosome transfer into damaged neurons and astrocytes. Sci Rep. 2016;6:24805.

86. Basmaeil YS, Algudiri D, Alenzi R, Al Subayyil A, Alaiya A, Khatlani T. HMOX1 is partly responsible for phenotypic and functional abnormalities in mesenchymal stem cells/stromal cells from placenta of preeclampsia (PE) patients. Stem Cell Res Ther. 2020;11(1):30.

87. Capilla-Gonzalez V, Lopez-Beas J, Escacena N, Aguilera Y, de la Cuesta A, Ruiz-Salmeron $\mathrm{R}$, et al. PDGF restores the defective phenotype of adiposederived mesenchymal stromal cells from diabetic patients. Mol Ther. 2018; 26(11):2696-709.

88. Jain A, Khadwal A, Sachdeva MUS, Bose P, Lad D, Bhattacharya S, et al. Variables affecting the presence of mesenchymal stromal cells in peripheral blood and their relationship with apheresis products. Brit J Haematol. 2020;189(4):772-6.

89. Liu W, Wang Y, Gong F, Rong Y, Luo Y, Tang P, et al. Exosomes derived from bone mesenchymal stem cells repair traumatic spinal cord injury by suppressing the activation of $\mathrm{A} 1$ neurotoxic reactive astrocytes. J Neurotrauma. 2019:36(3):469-84.

90. Takov K, He Z, Johnston HE, Timms JF, Guillot PV, Yellon DM, et al. Small extracellular vesicles secreted from human amniotic fluid mesenchymal stromal cells possess cardioprotective and promigratory potential. Basic Res Cardiol. 2020;115(3):26

91. Thomi G, Joerger-Messerli M, Haesler V, Muri L, Surbek D, Schoeberlein A. Intranasally administered exosomes from umbilical cord stem cells have preventive neuroprotective effects and contribute to functional recovery after perinatal brain injury. Cells. 2019;8(8):855.

92. Dominici M, Le Blanc K, Mueller I, Slaper-Cortenbach I, Marini F, Krause D, et al. Minimal criteria for defining multipotent mesenchymal stromal cells. The International Society for Cellular Therapy position statement. Cytotherapy. 2006:8(4):315-7.

93. Park KS, Bandeira E, Shelke GV, Lasser C, Lotvall J. Enhancement of therapeutic potential of mesenchymal stem cell-derived extracellular vesicles. Stem Cell Res Ther. 2019;10(1):288.

94. Mikael PE, Willard C, Koyee A, Barlao CG, Liu X, Han X, et al. Remodeling of glycosaminoglycans during differentiation of adult human bone mesenchymal stromal cells toward hepatocytes. Stem Cells Dev. 2019;28(4):278-89.

95. Urrutia DN, Caviedes P, Mardones R, Minguell JJ, Vega-Letter AM, Jofre CM Comparative study of the neural differentiation capacity of mesenchymal stromal cells from different tissue sources: an approach for their use in neural regeneration therapies. PLoS One. 2019;14(3):e0213032.

96. Yoshida S, Miyagawa S, Toyofuku T, Fukushima S, Kawamura T, Kawamura A, et al. Syngeneic mesenchymal stem cells reduce immune rejection after induced pluripotent stem cell-derived allogeneic cardiomyocyte transplantation. Sci Rep. 2020;10(1):4593.

97. Yin Z, Han Z, Hu T, Zhang S, Ge X, Huang S, et al. Neuron-derived exosomes with high miR-21-5p expression promoted polarization of M1 microglia in culture. Brain Behav Immun. 2020;83:270-82.

98. Huang S, Ge X, Yu J, Han Z, Yin Z, Li Y, et al. Increased miR-124-3p in microglial exosomes following traumatic brain injury inhibits neuronal inflammation and contributes to neurite outgrowth via their transfer into neurons. FASEB J. 2018;32(1):512-28.

99. Xian P, Hei Y, Wang R, Wang T, Yang J, Li J, et al. Mesenchymal stem cellderived exosomes as a nanotherapeutic agent for amelioration of inflammation-induced astrocyte alterations in mice. Theranostics. 2019;9(20): 5956-75.

100. Nocera AL, Mueller SK, Stephan JR, Hing L, Seifert P, Han X, et al. Exosome swarms eliminate airway pathogens and provide passive epithelial immunoprotection through nitric oxide. J Allergy Clin Immunol. 2019;143(4): 1525-35. e1.

101. Gamez-Valero A, Monguio-Tortajada M, Carreras-Planella L, Franquesa M, Beyer K, Borras FE. Size-exclusion chromatography-based isolation minimally alters extracellular vesicles' characteristics compared to precipitating agents. Sci Rep. 2016;6:33641.
102. Blans K, Hansen MS, Sorensen LV, Hvam ML, Howard KA, Moller A, et al. Pellet-free isolation of human and bovine milk extracellular vesicles by sizeexclusion chromatography. J Extracellular Vesicles. 2017;6(1):1294340.

103. Wei Z, Batagov AO, Schinelli S, Wang J, Wang Y, El Fatimy R, et al. Coding and noncoding landscape of extracellular RNA released by human glioma stem cells. Nat Commun. 2017:8(1):1145.

104. Lobb RJ, Becker M, Wen SW, Wong CS, Wiegmans AP, Leimgruber A, et al. Optimized exosome isolation protocol for cell culture supernatant and human plasma. J Extracellular Vesicles. 2015;4:27031.

105. Ge X, Guo M, Hu T, Li W, Huang S, Yin Z, et al. Increased microglial Exosomal miR-124-3p alleviates neurodegeneration and improves cognitive outcome after rmTBI. Mol Ther. 2020;28(2):503-22.

106. Sitar S, Kejzar A, Pahovnik D, Kogej K, Tusek-Znidaric M, Lenassi M, et al. Size characterization and quantification of exosomes by asymmetrical-flow fieldflow fractionation. Anal Chem. 2015;87(18):9225-33.

107. Kormelink TG, Arkesteijn GJA, Nauwelaers FA, van den Engh G, Nolte-'t Hoen ENM, Wauben MHM. Prerequisites for the analysis and sorting of extracellular vesicle subpopulations by high-resolution flow cytometry. Cytometry Part A. 2016;89(2):135-47.

108. Kanwar SS, Dunlay CJ, Simeone DM, Nagrath S. Microfluidic device (ExoChip) for on-chip isolation, quantification and characterization of circulating exosomes. Lab Chip. 2014;14(11):1891-900.

109. Harrell CR, Fellabaum C, Jovicic N, Djonov V, Arsenijevic N, Volarevic V. Molecular mechanisms responsible for therapeutic potential of mesenchymal stem cell-derived secretome. Cells. 2019;8(5):467.

110. Jhala D, Rather HA, Vasita R. Extracellular matrix mimicking polycaprolactonechitosan nanofibers promote stemness maintenance of mesenchymal stem cells via spheroid formation. Biomed Mater. 2020;15(3):035011.

111. Ding $M$, Shen $Y$, Wang $P$, Xie Z, Xu S, Zhu Z, et al. Exosomes isolated from human umbilical cord mesenchymal stem cells alleviate neuroinflammation and reduce amyloid-Beta deposition by modulating microglial activation in Alzheimer's disease. Neurochem Res. 2018:43(11):2165-77.

112. Katsuda T, Tsuchiya R, Kosaka N, Yoshioka Y, Takagaki K, Oki K, et al. Human adipose tissue-derived mesenchymal stem cells secrete functional neprilysin-bound exosomes. Sci Rep. 2013;3:1197.

113. Wang SS, Jia J, Wang Z. Mesenchymal stem cell-derived extracellular vesicles suppresses iNOS expression and ameliorates neural impairment in Alzheimer's disease mice. J Alzheimers Dis. 2018;61(3):1005-13.

114. Cui GH, Wu J, Mou FF, Xie WH, Wang FB, Wang QL, et al. Exosomes derived from hypoxia-preconditioned mesenchymal stromal cells ameliorate cognitive decline by rescuing synaptic dysfunction and regulating inflammatory responses in APP/PS1 mice. FASEB J. 2018;32(2):654-68.

115. Bodart-Santos V, de Carvalho LRP, de Godoy MA, Batista AF, Saraiva LM Lima LG, et al. Extracellular vesicles derived from human Wharton's jelly mesenchymal stem cells protect hippocampal neurons from oxidative stress and synapse damage induced by amyloid-beta oligomers. Stem Cell Res Ther. 2019;10(1):332.

116. de Godoy MA, Saraiva LM, de Carvalho LRP, Vasconcelos-Dos-Santos A, Beira HJV, Ramos AB, et al. Mesenchymal stem cells and cell-derived extracellular vesicles protect hippocampal neurons from oxidative stress and synapse damage induced by amyloid-beta oligomers. J Biol Chem. 2018;293(6):1957-75.

117. Lee M, Ban JJ, Yang S, Im W, Kim M. The exosome of adipose-derived stem cells reduces beta-amyloid pathology and apoptosis of neuronal cells derived from the transgenic mouse model of Alzheimer's disease. Brain Res. 2018;1691:87-93.

118. Elia CA, Tamborini M, Rasile M, Desiato G, Marchetti S, Swuec P, et al. Intracerebral injection of extracellular vesicles from mesenchymal stem cells exerts reduced abeta plaque burden in early stages of a preclinical model of Alzheimer's disease. Cells. 2019;8(9):1059.

119. Yang L, Zhai $Y$, Hao $Y$, Zhu Z, Cheng G. The regulatory functionality of exosomes derived from hUMSCs in 3D culture for Alzheimer's disease therapy. Small. 2020;16(3):e1906273.

120. Linares R, Tan S, Gounou C, Arraud N, Brisson AR. High-speed centrifugation induces aggregation of extracellular vesicles. J Extracell Vesicles. 2015:4:29509.

121. Lasser C, Eldh M, Lotvall J. Isolation and characterization of RNA-containing exosomes. J Vis Exp. 2012;(59):e3037.

122. Carnino JM, Lee H, Jin Y. Isolation and characterization of extracellular vesicles from Broncho-alveolar lavage fluid: a review and comparison of different methods. Respir Res. 2019;20(1):240.

123. Taylor DD, Shah S. Methods of isolating extracellular vesicles impact downstream analyses of their cargoes. Methods. 2015;87:3-10. 
124. Sharma P, Ludwig S, Muller L, Hong CS, Kirkwood JM, Ferrone S, et al. Immunoaffinity-based isolation of melanoma cell-derived exosomes from plasma of patients with melanoma. J Extracell Vesicles. 2018;7(1):1435138.

125. Konoshenko MY, Lekchnov EA, Vlassov AV, Laktionov PP. Isolation of extracellular vesicles: general methodologies and latest trends. Biomed Res Int. 2018;2018:8545347.

126. Tian Y, Gong M, Hu Y, Liu H, Zhang W, Zhang M, et al. Quality and efficiency assessment of six extracellular vesicle isolation methods by nanoflow cytometry. J Extracellular Vesicles. 2020;9(1):1697028.

127. Groot Kormelink T, Arkesteijn GJ, Nauwelaers FA, van den Engh G, Nolte-'t Hoen EN, Wauben $\mathrm{MH}$. Prerequisites for the analysis and sorting of extracellular vesicle subpopulations by high-resolution flow cytometry. Cytometry A. 2016;89(2):135-47.

128. Pospichalova V, Svoboda J, Dave Z, Kotrbova A, Kaiser K, Klemova D, et al. Simplified protocol for flow cytometry analysis of fluorescently labeled exosomes and microvesicles using dedicated flow cytometer. J Extracell Vesicles. 2015;4:25530.

129. Gandham S, Su X, Wood J, Nocera AL, Alli SC, Milane L. et al, Technologies and standardization in research on extracellular vesicles. Trends Biotechnol. 2020:S0167-7799(20)30163-3.

130. Chen J, Chopp M. Exosome therapy for stroke. Stroke. 2018;49(5):1083-90.

131. Kusuma GD, Barabadi M, Tan JL, Morton DAV, Frith JE, Lim R. To protect and to preserve: novel preservation strategies for extracellular vesicles. Front Pharmacol. 2018;9:1199.

132. Harrell CR, Jovicic N, Djonov V, Volarevic V. Therapeutic use of mesenchymal stem cell-derived exosomes: from basic science to clinics. Pharmaceutics. 2020;12(5):474.

133. Mead B, Amaral J, Tomarev S. Mesenchymal stem cell-derived small extracellular vesicles promote neuroprotection in rodent models of glaucoma. Invest Ophthalmol Vis Sci. 2018;59(2):702-14.

134. Bruno S, Grange C, Deregibus MC, Calogero RA, Saviozzi S, Collino F, et al. Mesenchymal stem cell-derived microvesicles protect against acute tubular injury. J Am Soc Nephrol. 2009;20(5):1053-67.

135. Vardy ER, Catto AJ, Hooper NM. Proteolytic mechanisms in amyloid-beta metabolism: therapeutic implications for Alzheimer's disease. Trends Mol Med. 2005;11(10):464-72

136. Yuyama K, Sun H, Usuki S, Sakai S, Hanamatsu H, Mioka T, et al. A potential function for neuronal exosomes: sequestering intracerebral amyloid- $\beta$ peptide. FEBS Lett. 2015;589(1):84-8.

137. de Dios C, Bartolessis I, Roca-Agujetas V, Barbero-Camps E, Mari M, Morales A, et al. Oxidative inactivation of amyloid beta-degrading proteases by cholesterol-enhanced mitochondrial stress. Redox Biol. 2019;26:101283.

138. Iwata N, Tsubuki S, Takaki Y, Watanabe K, Sekiguchi M, Hosoki E, et al. Identification of the major Aß1-42-degrading catabolic pathway in brain parenchyma: suppression leads to biochemical and pathological deposition. Nat Med. 2000;6(2):143-50.

139. Iwata N, Tsubuki S, Takaki Y, Shirotani K, Lu B, Gerard NP, et al. Metabolic regulation of brain Abeta by neprilysin. Science. 2001;292(5521):1550-2.

140. Farris W, Mansourian S, Chang Y, Lindsley L, Eckman EA, Frosch MP, et al. Insulin-degrading enzyme regulates the levels of insulin, amyloid betaprotein, and the beta-amyloid precursor protein intracellular domain in vivo. Proc Natl Acad Sci U S A. 2003;100(7):4162-7.

141. Del Fattore A, Luciano R, Pascucci L, Goffredo BM, Giorda E, Scapaticci M, et al. Immunoregulatory effects of Mesenchymal stem cell-derived extracellular vesicles on T lymphocytes. Cell Transplant. 2015:24(12):2615-27.

142. Blazquez R, Sanchez-Margallo FM, de la Rosa O, Dalemans W, Alvarez V, Tarazona $\mathrm{R}$, et al. Immunomodulatory potential of human adipose mesenchymal stem cells derived exosomes on in vitro stimulated T cells. Front Immunol. 2014;5:556.

143. Xie $M$, Xiong W, She Z, Wen Z, Abdirahman AS, Wan W, et al. Immunoregulatory effects of stem cell-derived extracellular vesicles on immune cells. Front Immunol. 2020;11:13.

144. Chen W, Huang Y, Han J, Yu L, Li Y, Lu Z, et al. Immunomodulatory effects of mesenchymal stromal cells-derived exosome. Immunol Res. 2016;64(4):831-40.

145. Ising C, Venegas C, Zhang S, Scheiblich H, Schmidt SV, Vieira-Saecker A, et al. NLRP3 inflammasome activation drives tau pathology. Nature. 2019; 575(7784):669-73.

146. Wu H, Fan H, Shou Z, Xu M, Chen Q, Ai C, et al. Extracellular vesicles containing miR-146a attenuate experimental colitis by targeting TRAF6 and IRAK1. Int Immunopharmacol. 2019:68:204-12.
147. Togo T, Katsuse O, Iseki E. Nitric oxide pathways in Alzheimer's disease and other neurodegenerative dementias. Neurol Res. 2004;26(5):563-6.

148. Wolf SA, Boddeke HW, Kettenmann H. Microglia in physiology and disease. Annu Rev Physiol. 2017;79:619-43.

149. Miya Shaik M, Tamargo IA, Abubakar MB, Kamal MA, Greig NH, Gan SH. The role of microRNAs in Alzheimer's disease and their therapeutic potentials. Genes. 2018;9(4):174

150. Cheng X, Zhang G, Zhang L, Hu Y, Zhang K, Sun X, et al. Mesenchymal stem cells deliver exogenous miR-21 via exosomes to inhibit nucleus pulposus cell apoptosis and reduce intervertebral disc degeneration. J Cell Mol Med. 2018; 22(1):261-76.

151. Reza-Zaldivar EE, Hernandez-Sapiens MA, Minjarez B, Gutierrez-Mercado YK, Marquez-Aguirre AL, Canales-Aguirre AA. Potential effects of MSC-derived exosomes in neuroplasticity in Alzheimer's disease. Front Cell Neurosci. 2018;12:317.

152. Xin H, Li Y, Liu Z, Wang X, Shang X, Cui Y, et al. MiR-133b promotes neural plasticity and functional recovery after treatment of stroke with multipotent mesenchymal stromal cells in rats via transfer of exosome-enriched extracellular particles. Stem Cells. 2013;31(12):2737-46.

153. Chen SY, Lin MC, Tsai JS, He PL, Luo WT, Herschman H, et al. EP4 antagonist-elicited extracellular vesicles from mesenchymal stem cells rescue cognition/learning deficiencies by restoring brain cellular functions. Stem Cells Transl Med. 2019;8(7):707-23.

154. Elia CA, Losurdo M, Malosio ML, Coco S. Extracellular vesicles from mesenchymal stem cells exert pleiotropic effects on amyloid-beta, inflammation, and regeneration: a spark of hope for Alzheimer's disease from tiny structures? Bioessays. 2019;41(4):e1800199.

155. Nassar W, El-Ansary M, Sabry D, Mostafa MA, Fayad T, Kotb E, et al. Umbilical cord mesenchymal stem cells derived extracellular vesicles can safely ameliorate the progression of chronic kidney diseases. Biomater Res. 2016;20:21.

156. Jeong JO, Han JW, Kim JM, Cho HJ, Park C, Lee N, et al. Malignant tumor formation after transplantation of short-term cultured bone marrow mesenchymal stem cells in experimental myocardial infarction and diabetic neuropathy. Circ Res. 2011;108(11):1340-7.

157. Fan B, Li C, Szalad A, Wang L, Pan W, Zhang R, et al. Mesenchymal stromal cell-derived exosomes ameliorate peripheral neuropathy in a mouse model of diabetes. Diabetologia. 2020;63(2):431-43.

158. Phinney DG, Pittenger MF. Concise review: MSC-derived exosomes for cellfree therapy. Stem Cells. 2017;35(4):851-8.

159. Gorabi AM, Kiaie N, Barreto GE, Read MI, Tafti HA, Sahebkar A. The therapeutic potential of mesenchymal stem cell-derived exosomes in treatment of neurodegenerative diseases. Mol Neurobiol. 2019;56(12):8157-67.

160. Stremersch S, De Smedt SC, Raemdonck K. Therapeutic and diagnostic applications of extracellular vesicles. J Control Release. 2016;244:167-83.

161. Yeo RW, Lai RC, Zhang B, Tan SS, Yin Y, Teh BJ, et al. Mesenchymal stem cell: an efficient mass producer of exosomes for drug delivery. Adv Drug Deliv Rev. 2013;65(3):336-41.

162. Cai J, Wu J, Wang J, Li Y, Hu X, Luo S, et al. Extracellular vesicles derived from different sources of mesenchymal stem cells: therapeutic effects and translational potential. Cell Bioscience. 2020;10:69.

163. Kawikova I, Askenase PW. Diagnostic and therapeutic potentials of exosomes in CNS diseases. Brain Res. 2015;1617:63-71.

164. Imbimbo BP, Lozupone M, Watling M, Panza F. Discontinued disease-modifying therapies for Alzheimer's disease: status and future perspectives. Expert Opin Investig Drugs. 2020:1-15 https://pubmed.ncbi.nlm.nih.gov/32657175/.

165. Egan MF, Kost J, Voss T, Mukai Y, Aisen PS, Cummings JL, et al. Randomized trial of verubecestat for prodromal Alzheimer's disease. N Engl J Med. 2019; 380(15):1408-20

\section{Publisher's Note}

Springer Nature remains neutral with regard to jurisdictional claims in published maps and institutional affiliations. 